\title{
Association of Lifestyle with Serum Lipid Levels: a Study of Middle-Aged Japanese Men
}

\author{
Noriyuki Nakanishi ${ }^{1}$, Kozo Tatara ${ }^{1}$, Koji Nakamura ${ }^{2}$, and Kenji Suzuki ${ }^{3}$
}

\begin{abstract}
Cross-sectional associations between lifestyle and serum lipid levels were examined in 1591 Japanese male office workers aged 35 to 59 years in Osaka, Japan. From multiple linear regression analyses, significant correlates with low-density lipoprotein (LDL) cholesterol, highdensity lipoprotein (HDL) cholesterol, and Log triglyceride levels and the ratio of LDL cholesterol to HDL cholesterol were, in the order of relative importance: BMI, alcohol intake (negative) and age for LDL cholesterol level; BMI (negative), cigarette smoking (negative), alcohol intake, consideration for nutritional balance, hours of brisk walking, hours of walking at an ordinary pace and physical exercise for HDL cholesterol level; BMI, cigarette smoking, consideration for nutritional balance (negative), hours of work (negative), alcohol intake and coffee drinking (negative) for Log triglyceride level; and BMI, alcohol intake (negative), cigarette smoking, consideration for nutritional balance (negative), age, hours of brisk walking (negative) and the frequency of snack intake between meals for the ratio of LDL cholesterol to HDL cholesterol. Our data suggest that obesity, cigarette smoking and snack intake between meals are atherogenic whereas alcohol consumption, consideration for nutritional balance and walking long hours, especially at a brisk pace, are anti-atherogenic in middle-aged Japanese men.
\end{abstract}

J Epidemiol, $2000 ; 10: 216-225$.

Japanese men, lifestyle, lipids, middle age

The relationship between serum lipids and coronary heart disease (CHD) is well established ${ }^{1-3)}$. A direct relationship is reported between elevated low-density lipoprotein (LDL) cholesterol level and the risk of developing CHD whereas the elevated level of high-density lipoprotein (HDL) cholesterol is reported to decrease the risk of developing $\mathrm{CHD}^{2,3)}$. Of lifestyle factors associated with serum lipids, obesity is known to be atherogenic primarily by increasing LDL cholesterol level and decreasing $\mathrm{HDL}$ cholesterol level ${ }^{4-8}$. Smoking also results in an atherogenic lipid profile by decreasing HDL cholesterol ${ }^{811)}$. On the other hand, alcohol intake and physical activity increase HDL cholesterol level, thereby conferring anti-atherogenic properties ${ }^{6,8,12-18)}$. However, few studies have evaluated the relative importance of lifestyle factors in the variation of atherogenicity of serum lipid profiles ${ }^{8,19,20)}$.

To promote primary prevention of lipid disorders at the workplace, it is crucial to be aware of lifestyle factors which can influence serum lipid levels. Knowledge of lifestyle factors related to serum lipid levels would allow planners of health care to focus on primary prevention efforts for the highest risk groups. In this report on a cross-sectional population study based on annual health examinations at the workplace, we have made an attempt to evaluate the association of lifestyle factors with serum lipid profiles in middle-aged Japanese men.

Received ; September 8, 1999 ; accepted November 15, 1999.

' Department of Social and Environmental Medicine F2,Course of Social Medicine, Osaka University Graduate School of Medicine.

${ }^{2}$ Medical Office, Osaka Main Office, Takenaka Corporation.

3 Japan Labor and Welfare Association.

Address for correspondence: Noriyuki Nakanishi, Department of Social and Environmental Medicine F2, Course of Social Medicine, Osaka University Graduate School of Medicine, 2-2 Yamada-oka, Suita-shi, Osaka 565-0871 Japan. 


\section{MATERIALS AND METHODS}

A survey to evaluate lifestyle factors related to serum lipid profiles was conducted in 1994 among employees of $\mathrm{T}$ Corporation, which is one of the biggest building contractors in Osaka, Japan. The surveillance population in May 1994 consisted of 1580 Japanese male office workers aged 35 to 59 years, and the participation rate was $99.9 \%$.

The survey included a questionnaire on lifestyle, physical examinations and collection of blood samples for laboratory analysis. Data on lifestyle were obtained by interview. Selected items of lifestyle for this study were as follows: overall obesity, alcohol intake, cigarette smoking, eating breakfast, snack intake between meals, physical exercise, hours of sleep, consideration for nutritional balance, hours of work, coffee drinking and hours of walking at an ordinary pace and/or at a brisk pace. The former seven items of lifestyle have been identified as healthy lifestyle indices in the studies of Belloc and Breslow ${ }^{21)}$ and the following two items (consideration for nutritional balance and hours of work) have been recommended by Morimoto et al. ${ }^{22}$, composed of eight items on healthy lifestyle for use in a study in Japan, based on that of Belloc and Breslow. Body mass index (BMI) was used as a measure of overall obesity. Weight and height were measured with the subjects wearing typical indoor clothing but with their shoes off, and BMI was calculated as weight $/$ height $^{2}\left(\mathrm{~kg} / \mathrm{m}^{2}\right)$. Alcohol intake was obtained by interview as usual weekly intake of alcohol in go (a traditional Japanese unit of volume corresponding to $23 \mathrm{~g}$ ethanol) and converted to grams of ethanol per day. One go is $180 \mathrm{ml}$ of sake and corresponds to one bottle of beer $(633 \mathrm{ml})$, two shots $(70 \mathrm{ml})$ of whisky, or two glasses $(180 \mathrm{ml})$ of wine. As for coffee drinking, examinees were asked their usual daily intake in cups, but information on the brewing method of coffee was not collected. Information of walking hours was based on the following question: 'How long do you usually walk at an ordinary pace (4 kilometers an hour on average for Japanese) and/or at a brisk pace a day, except for working hours?', which could be answered in minutes. Nineteen subjects were under medication for dyslipidemia, and the remaining 1561 subjects constituted the study population. Data on lifestyle were grouped into three subgroups as shown in Table 1. Fasting blood samples were drawn from an antecubital vein. Serum total cholesterol, HDL cholesterol and triglyceride were analyzed with Olympus AU5000 (Olympus Japan Co., Ltd., Tokyo, Japan) by the Nihon Clinical Laboratories Inc. (Tokyo, Japan). The level of LDL cholesterol was calculated from total cholesterol, HDL cholesterol and triglyceride using Friedewald's formula (LDL cholesterol $=$ total cholesterol - HDL cholesterol - triglyceride/5) in the subjects whose serum triglyceride level was $<400 \mathrm{mg} / \mathrm{dl}^{23}$ ). The triglyceride value was $\geq 400 \mathrm{mg} / \mathrm{dl}$ in 42 subjects $(2.7 \%$ ), and we excluded these cases showing this value from statistical analysis involving LDL cholesterol.
For statistical assessment, analysis of covariance was used to compare the age-adjusted means of serum lipids among the three subgroups of lifestyle. Stepwise multiple regression analyses were performed to examine an independent association of lifestyle factors and their relative importance as determinants of serum lipids. In the statistical analyses, the logarithm for the triglyceride (because of the non-gaussian distribution of the frequency for this variable) was used.

Data analysis was performed with the SPSS/PC statistical package (Marija J. Norusis, SPSS Inc., Chicago, IL, USA). All reported p-values are two-tailed and a p-value of less than 0.05 was considered significant.

\section{RESULTS}

Characteristics of the study subjects are summarized in Table 1 . The mean values of LDL cholesterol and HDL cholesterol levels and the ratio of LDL cholesterol to HDL cholesterol were $116.6 \mathrm{mg} / \mathrm{dl}$ (standard deviation; $28.7 \mathrm{mg} / \mathrm{dl}$ ), 53.3 $\mathrm{mg} / \mathrm{dl}(12.0 \mathrm{mg} / \mathrm{dl})$ and $2.29(0.78)$, respectively. The frequency distributions of LDL cholesterol and HDL cholesterol levels and the ratio of LDL cholesterol to HDL cholesterol showed unimodal curves with medians of $114.4 \mathrm{mg} / \mathrm{dl}, 53 \mathrm{mg} / \mathrm{dl}$ and 2.19 , respectively. The mean $\log$ triglyceride level was 4.72 $\mathrm{mg} / \mathrm{dl}$ with the standard deviation of $0.59 \mathrm{mg} / \mathrm{dl}$, and the frequency distribution of $\mathrm{Log}$ triglyceride showed some skewing to the right with a median of $4.64 \mathrm{mg} / \mathrm{dl}$. There were no definite differences in lifestyle between all 1561 subjects of this study and 1519 subjects whose LDL cholesterol levels were available for.

The age-adjusted means of LDL cholesterol, HDL cholesterol and Log triglyceride levels and the ratio of LDL cholesterol to HDL cholesterol by lifestyle are shown in Table 2 . Age-adjusted means of LDL cholesterol level were significantly different among the three subgroups of BMI, alcohol intake, cigarette smoking, eating breakfast and snack intake between meals. LDL cholesterol levels increased with an increase in BMI or with the increased frequency of snack intake between meals. Age-adjusted means of LDL cholesterol level were lower in those who drank alcohol daily than in those who did not, and were also lower in those who smoked currently than in those who did not. Age-adjusted means of LDL cholesterol level were higher in those who ate breakfast sometimes or everyday than in those who did not.

Age-adjusted means of HDL cholesterol differed significantly among the three subgroups of BMI, alcohol intake, cigarette smoking, snack intake between meals, consideration for nutritional balance, coffee drinking, hours of walking at an ordinary pace or at a brisk pace and physical exercise. Age-adjusted means of HDL cholesterol decreased with an increase in BMI, cigarette smoking, or the frequency of snack intake between meals. On the other hand, age-adjusted means of HDL cholesterol increased with an increase in alcohol intake, consideration 
Table 1. Characteristics of 1561 Japanese male office workers aged 35 to 59 years.

\begin{tabular}{|c|c|c|c|}
\hline \multicolumn{2}{|l|}{ Variable (Unit) } & \multicolumn{2}{|c|}{$\begin{array}{l}\text { Mean } \pm \text { standard deviation } \\
\text { or proportion }\end{array}$} \\
\hline \multicolumn{2}{|l|}{ Age (years) } & \multicolumn{2}{|c|}{$47.4 \pm 6.2$} \\
\hline \multicolumn{2}{|l|}{ LDL cholesterol $(\mathrm{mg} / \mathrm{dl})^{*}$} & \multicolumn{2}{|c|}{$116.6 \pm 28.7$} \\
\hline \multicolumn{2}{|l|}{ HDL cholesterol (mg/dl) } & \multicolumn{2}{|c|}{$53.3 \pm 12.0$} \\
\hline \multicolumn{2}{|l|}{ Log triglyceride $(\mathrm{mg} / \mathrm{dl})$} & \multicolumn{2}{|c|}{$4.72 \pm 0.59$} \\
\hline \multicolumn{2}{|l|}{ Ratio of LDL cholesterol to HDL cholesterol* } & \multicolumn{2}{|c|}{$2.29 \pm 0.78$} \\
\hline \multirow[t]{3}{*}{ Body mass index $\left(\mathrm{kg} / \mathrm{m}^{2}\right)$} & $\leq 21.9$ & $29.3 \%$ & $(29.9 \%)^{*}$ \\
\hline & $22.0-24.1$ & $36.0 \%$ & $(36.1 \%)$ \\
\hline & $\geq 24.2$ & $34.7 \%$ & $(34.0 \%)$ \\
\hline \multirow[t]{3}{*}{ Alcohol intake ( $\mathrm{g} /$ day of ethanol) } & None & $37.7 \%$ & $(37.8 \%)$ \\
\hline & $\leq 45.9$ & $44.7 \%$ & $(45.0 \%)$ \\
\hline & $\geq 46.0$ & $17.6 \%$ & $(17.2 \%)$ \\
\hline \multirow[t]{3}{*}{ Smoking (cigarettes/day) } & None & $49.4 \%$ & $(49.6 \%)$ \\
\hline & $\leq 29$ & $25.8 \%$ & $(25.7 \%)$ \\
\hline & $\geq 30$ & $24.8 \%$ & $(24.6 \%)$ \\
\hline \multirow[t]{3}{*}{ Eating breakfast } & Hardly ever & $10.2 \%$ & $(10.1 \%)$ \\
\hline & Sometimes & $4.5 \%$ & $(4.4 \%)$ \\
\hline & Every morning & $85.2 \%$ & $(85.5 \%)$ \\
\hline \multirow[t]{3}{*}{ Snack intake between meals } & Hardly ever & $55.6 \%$ & $(55.7 \%)$ \\
\hline & Sometimes & $33.1 \%$ & $(33.1 \%)$ \\
\hline & Every day & $11.3 \%$ & $(11.2 \%)$ \\
\hline \multirow[t]{3}{*}{ Consideration for nutritional balance } & Hardly ever & $6.7 \%$ & $(6.4 \%)$ \\
\hline & Sometimes & $33.7 \%$ & $(33.8 \%)$ \\
\hline & Always & $59.6 \%$ & $(59.8 \%)$ \\
\hline \multirow[t]{3}{*}{ Coffee drinking (cups/day) } & Hardly ever & $15.5 \%$ & $(15.9 \%)$ \\
\hline & 1 or 2 & $55.2 \%$ & $(54.7 \%)$ \\
\hline & 3 or more & $29.3 \%$ & $(29.4 \%)$ \\
\hline \multirow[t]{3}{*}{ Hours of walking at ordinary speed (hours/day) } & $<0.5$ & $40.0 \%$ & $(40.2 \%)$ \\
\hline & $0.5-0.9$ & $42.0 \%$ & $(41.9 \%)$ \\
\hline & $\geq 1.0$ & $18.0 \%$ & $(17.9 \%)$ \\
\hline \multirow[t]{3}{*}{ Hours of brisk walking (hours/day) } & $<0.5$ & $51.4 \%$ & $(51.4 \%)$ \\
\hline & $0.5-0.9$ & $32.9 \%$ & $(32.9 \%)$ \\
\hline & $\geq 1.0$ & $15.7 \%$ & $(15.7 \%)$ \\
\hline \multirow[t]{3}{*}{ Hours of working (hours/day) } & $\leq 8.0$ & $49.5 \%$ & $(48.8 \%)$ \\
\hline & $8.1-9.9$ & $24.5 \%$ & $(25.0 \%)$ \\
\hline & $\geq 10.0$ & $26.0 \%$ & $(26.3 \%)$ \\
\hline \multirow[t]{3}{*}{ Physical exercise (times/week) } & Hardly ever & $46.1 \%$ & $(45.9 \%)$ \\
\hline & Once & $38.5 \%$ & $(38.6 \%)$ \\
\hline & Twice or more & $15.4 \%$ & $(15.5 \%)$ \\
\hline \multirow[t]{3}{*}{ Hours of sleeping (hours/night) } & $\leq 6.4$ & $40.4 \%$ & $(40.6 \%)$ \\
\hline & $6.5-7.4$ & $47.8 \%$ & $(47.7 \%)$ \\
\hline & $\geq 7.5$ & $11.9 \%$ & $(11.8 \%)$ \\
\hline
\end{tabular}

* Data for LDL cholesterol were available for 1519 men.

In parentheses are the percentages of men whose LDL cholesterol were available for.

for nutritional balance or the frequency of physical exercise Age-adjusted means of HDL cholesterol were lower in those who consumed 3 cups/day of coffee or more than in those who consumed coffee hardly ever or who consumed less than 3 cups/day of coffee. Furthermore, age-adjusted means of HDL cholesterol were lower in those who walked at an ordinary pace or at a brisk pace less than 0.5 hours a day than in those who walked an ordinary pace or at a brisk pace 0.5 hours a day or more.

As for the Log triglyceride level, age-adjusted means of $\mathrm{Log}$ triglyceride level were significantly different among the three subgroups of BMI, alcohol intake, cigarette smoking, consideration for nutritional balance and hours of work. Log triglyceride levels increased with increasing BMI and cigarette smoking. The subjects who drank $46.0 \mathrm{~g} /$ day of ethanol or more had the higher levels of Log triglyceride than those who did not 
Table 2. Age-adjusted means of LDL cholesterol, HDL cholesterol and Log triglyceride levels and the ratio of LDL cholesterol to HDL cholesterol according to lifestyle factors in 1561 Japanese male office workers.

\begin{tabular}{|c|c|c|c|c|c|}
\hline Variables & Subclass & $\begin{array}{c}\text { LDL } \\
\text { cholesterol* } \\
(\mathrm{mg} / \mathrm{dl})\end{array}$ & $\begin{array}{c}\text { HDL } \\
\text { cholesterol } \\
(\mathrm{mg} / \mathrm{dl})\end{array}$ & $\begin{array}{l}\text { Log } \\
\text { triglyceride } \\
(\mathrm{mg} / \mathrm{dl})\end{array}$ & $\begin{array}{l}\text { Ratio of } \\
\text { LDL chole- } \\
\text { sterol to HDL } \\
\text { cholesterol* }\end{array}$ \\
\hline Body mass index & $\leq 21.9$ & 109.8 & 57.9 & 4.46 & 2.00 \\
\hline \multirow[t]{3}{*}{$\left(\mathrm{kg} / \mathrm{m}^{2}\right)$} & $22.0-24.1$ & 116.9 & 52.8 & 4.76 & 2.30 \\
\hline & $\geq 24.2$ & 122.1 & 49.9 & 4.91 & 2.52 \\
\hline & Significance & $<0.001$ & $<0.001$ & $<0.001$ & $<0.001$ \\
\hline Alcohol intake & None & 120.3 & 50.8 & 4.70 & 2.46 \\
\hline \multirow[t]{3}{*}{ ( $g /$ day of ethanol) } & $\leq 45.9$ & 114.4 & 54.5 & 4.67 & 2.19 \\
\hline & $\geq 46.0$ & 114.2 & 55.4 & 4.89 & 2.16 \\
\hline & Significance & $<0.001$ & $<0.001$ & $<0.001$ & $<0.001$ \\
\hline Smoking & None & 118.3 & 55.5 & 4.65 & 2.22 \\
\hline \multirow[t]{3}{*}{ (cigarettes/day) } & $\leq 29$ & 113.5 & 52.1 & 4.74 & 2.29 \\
\hline & $\geq 30$ & 116.2 & 50.1 & 4.85 & 2.42 \\
\hline & Significance & 0.027 & $<0.001$ & $<0.001$ & $<0.001$ \\
\hline \multirow[t]{4}{*}{ Eating breakfast } & Hardly ever & 112.5 & 51.7 & 4.79 & 2.27 \\
\hline & Sometimes & 121.9 & 52.8 & 4.81 & 2.39 \\
\hline & Every morning & 116.5 & 53.5 & 4.70 & 2.28 \\
\hline & Significance & 0.020 & 0.209 & 0.091 & 0.537 \\
\hline \multirow[t]{4}{*}{ Snack intake between meals } & Hardly ever & 114.4 & 54.3 & 4.74 & 2.21 \\
\hline & Sometimes & 118.8 & 52.4 & 4.69 & 2.37 \\
\hline & Every day & 120.2 & 51.2 & 4.74 & 2.44 \\
\hline & Significance & 0.002 & 0.001 & 0.276 & $<0.001$ \\
\hline \multirow{4}{*}{$\begin{array}{l}\text { Consideration for nutritional } \\
\text { balance }\end{array}$} & Hardly ever & 117.1 & 51.0 & 4.84 & 2.35 \\
\hline & Sometimes & 117.1 & 52.2 & 4.74 & 2.35 \\
\hline & Always & 116.2 & 54.1 & 4.70 & 2.25 \\
\hline & Significance & 0.851 & 0.002 & 0.039 & 0.059 \\
\hline \multirow{4}{*}{$\begin{array}{l}\text { Coffee drinking } \\
\text { (cups/day) }\end{array}$} & Hardly ever & 115.4 & 53.5 & 4.72 & 2.25 \\
\hline & 1 or 2 & 116.0 & 54.0 & 4.74 & 2.25 \\
\hline & 3 or more & 118.5 & 51.8 & 4.69 & 2.39 \\
\hline & Significance & 0.264 & 0.005 & 0.475 & 0.004 \\
\hline \multirow{4}{*}{$\begin{array}{l}\text { Hours of walking at ordinary } \\
\text { speed (hours/day) }\end{array}$} & $<0.5$ & 116.2 & 52.0 & 4.72 & 2.30 \\
\hline & $0.5-0.9$ & 116.8 & 53.5 & 4.73 & 2.30 \\
\hline & $\geq 1.0$ & 117.4 & 55.5 & 4.69 & 2.22 \\
\hline & Significance & 0.839 & $<0.001$ & 0.575 & 0.326 \\
\hline \multirow{4}{*}{$\begin{array}{l}\text { Hours of brisk walking } \\
\text { (hours/day) }\end{array}$} & $<0.5$ & 116.8 & 51.6 & 4.74 & 2.35 \\
\hline & $0.5-0.9$ & 116.4 & 55.1 & 4.70 & 2.23 \\
\hline & $\geq 1.0$ & 116.5 & 54.9 & 4.71 & 2.21 \\
\hline & Significance & 0.974 & $<0.001$ & 0.366 & 0.007 \\
\hline \multirow{4}{*}{$\begin{array}{l}\text { Hours of working } \\
\text { (hours/day) }\end{array}$} & $\leq 8.0$ & 115.5 & 53.1 & 4.78 & 2.28 \\
\hline & $8.1-9.9$ & 119.3 & 53.1 & 4.67 & 2.35 \\
\hline & $\geq 10.0$ & 115.6 & 53.8 & 4.65 & 2.25 \\
\hline & Significance & 0.082 & 0.582 & $<0.001$ & 0.192 \\
\hline \multirow{4}{*}{$\begin{array}{l}\text { Physical exercise } \\
\text { (times/week) }\end{array}$} & Hardly ever & 116.4 & 52.4 & 4.72 & 2.32 \\
\hline & Once & 117.2 & 53.5 & 4.74 & 2.29 \\
\hline & Twice or more & 115.9 & 55.2 & 4.69 & 2.19 \\
\hline & Significance & 0.808 & 0.006 & 0.569 & 0.096 \\
\hline \multirow{4}{*}{$\begin{array}{l}\text { Hours of sleeping } \\
\text { (hours/night) }\end{array}$} & $\leq 6.4$ & 117.0 & 52.8 & 4.70 & 2.30 \\
\hline & $6.5-7.4$ & 116.7 & 53.8 & 4.73 & 2.27 \\
\hline & $\geq 7.5$ & 115.1 & 52.7 & 4.75 & 2.30 \\
\hline & Significance & 0.745 & 0.264 & 0.451 & 0.774 \\
\hline
\end{tabular}

*Data for LDL cholesterol were available for 1519 men.

Analysis of covariance was used to compare the age-adjusted means of serum lipid and lipoprotein levels among the three subclasses. 
drink alcohol or who drank less than $46.0 \mathrm{~g} /$ day of ethanol. Log triglyceride levels decreased with an increase in working hours.

Age-adjusted ratios of LDL cholesterol to HDL cholesterol differed significantly among the three subgroups of BMI, alcohol intake, cigarette smoking, snack intake between meals, coffee drinking and hours of brisk walking. Age-adjusted ratios of LDL cholesterol to HDL cholesterol increased with an increase in BMI, cigarette smoking, or the frequency of snack intake between meals. On the other hand, age-adjusted ratios of LDL cholesterol to HDL cholesterol decreased with an increase in alcohol intake. Age-adjusted ratios of LDL cholesterol to HDL cholesterol were lower in those who consumed 3 cups/day of coffee or more than in those who consumed coffee hardly ever or who consumed less than 3 cups/day of coffee, and were higher in those who walked at a brisk pace less than 0.5 hours a day than in those who walked at a brisk pace 0.5 hours a day or more.

Table 3 shows the results of multiple linear regression analyses for LDL cholesterol, HDL cholesterol and Log triglyceride levels and the ratio of LDL cholesterol to HDL cholesterol in relation to age and lifestyle factors. Independent and significant correlates with LDL cholesterol, HDL cholesterol and Log triglyceride levels and the ratio of LDL cholesterol to HDL cholesterol were, in the order of relative importance: BMI, alcohol intake (negative) and age for LDL cholesterol level; BMI (negative), cigarette smoking (negative), alcohol intake, consideration for nutritional balance, hours of brisk walking, hours of walking at an ordinary pace and physical exercise for HDL cholesterol level; BMI, cigarette smoking, consideration for nutritional balance (negative), hours of work (negative), alcohol intake and coffee drinking (negative) for Log triglyceride level; and BMI, alcohol intake (negative), cigarette smoking, consideration for nutritional balance (negative), age, hours of brisk walking (negative) and the frequency of snack intake between meals for the ratio of LDL cholesterol to HDL cholesterol. The cumulative percentages of variation for $\mathrm{LDL}$ cholesterol, HDL cholesterol and Log triglyceride levels and the ratio of LDL cholesterol to HDL cholesterol were $5.0 \%$, $17.8 \%, 15.5 \%$ and $13.8 \%$, respectively.

\section{DISCUSSION}

As expected, overall obesity indicated by BMI was found to be positively associated with LDL cholesterol and triglyceride levels and the ratio of LDL cholesterol to HDL cholesterol and negatively associated with HDL cholesterol level, and BMI was the most important factor for atherogenicity in serum lipid profiles. Obesity has been found to be accompanied by an increased risk of $\mathrm{CHD}^{24)}$, but whether obesity is an independent risk factor for CHD is still uncertain, since CHD is mediated mainly through the metabolic consequences of obesity: increased levels of LDL cholesterol ${ }^{487}$ and triglyceride ${ }^{5,6)}$ and reduced levels of $\mathrm{HDL}$ cholesterol ${ }^{68 \text { ) }}$ as well as hypertension ${ }^{25.26)}$ and glucose intolerance and diabetes mellitus ${ }^{27.283}$. However, the fact that weight reduction in obese patients affects these other risk factors for CHD makes obesity important in the treatment of lipid disorders ${ }^{18,29,30)}$. Although only $11.8 \%$ of our participants were deemed overweight (BMI $\geq 26.4 \mathrm{~kg} / \mathrm{m}^{2}$ ), obesity should be a major target for $\mathrm{CHD}$ prevention in middle-aged Japanese men.

We showed that alcohol intake was positively association with HDL cholesterol and triglyceride levels. On the other hand, alcohol intake had an inverse association with LDL cholesterol level and the ratio of LDL cholesterol to HDL cholesterol. These findings are consistent with the results of previous studies ${ }^{8,10,12-14)}$. It can therefore be suggested that alcohol has an anti-atherogenic effect by altering both HDL and LDL cholesterol, resulting in the decreased risk in serum lipid levels. However, clinical opinion holds that abstinence from alcohol is fundamental to the control of hypertriglyceridemia.

As for the effects of alcohol intake on health, an inverse association between drinking alcohol and the mortality and incidence of CHD have been found ${ }^{31-34}$. Reports from the Lipid Research Clinics Follow-up Study and a Multiple Risk Factor Intervention Trial have suggested that approximately $45-50 \%$ of the association between average alcohol consumption and death from CHD may be attributable to HDL cholesterol level ${ }^{35,36}$. Recent studies on the effect of alcohol on platelet function have revealed that platelet aggregation is significantly inhibited by alcohol, which might be another mechanism of protection from CHD in moderate drinkers ${ }^{37,38)}$. However, large amounts of alcohol intake are associated with higher risk of mortality from hypertension, stroke, cardiomyopathy and cirrhosis ${ }^{32}$, 33). Therefore, moderation in drinking should be recommended for the prevention of cardiovascular disease.

As for smoking, many studies have noted an inverse relationship between smoking and HDL cholesterol levels ${ }^{8-11)}$. The triglyceride level in whole serum and a very low density lipoprotein (VLDL) fraction have been also found to increase with cigarette smoking ${ }^{10}$. Phillips et al. ${ }^{10}$ have reported a positive association between the amount of cigarettes smoked and beta lipoproteins and posited that this effect is secondary to the higher VLDL triglyceride levels in smokers. We also showed that current cigarette smoking was negatively associated with HDL cholesterol level and positively associated with triglyceride level and the ratio of LDL cholesterol to HDL cholesterol. In the population surveyed for this study, more than half of our participants smoked cigarettes, smoking cessation is one of the most effective factors in health education programs at the workplace to reduce the risk of CHD.

Favorable effects of regular physical activity on increased levels of HDL cholesterol and reduced levels of triglyceride have been observed ${ }^{15-18}$. Nikkila et al. ${ }^{15}$ have reported that endurance training is associated with an adaptive increase in 
Table 3. Multiple linear regression analyses of LDL cholesterol, HDL cholesterol and Log triglyceridelevels and the ratio of LDL cholesterol to HDL cholesterol in relation to age and lifestyle factors.

\begin{tabular}{|c|c|c|c|c|}
\hline Variables & $\begin{array}{l}\text { Standardized } \\
\text { coefficient }\end{array}$ & $\begin{array}{c}\text { Natural } \\
\text { coefficient }\end{array}$ & $\mathrm{T}$ value & $P$ value \\
\hline \multicolumn{5}{|c|}{ LDL cholesterol } \\
\hline Age & 0.064 & 0.296 & 2.40 & 0.017 \\
\hline Body mass index & 0.179 & 1.929 & 6.99 & $<0.001$ \\
\hline Alcohol intake & -0.077 & -3.096 & -2.97 & 0.003 \\
\hline Smoking & -0.035 & -1.222 & -1.31 & 0.192 \\
\hline Eating breakfast & 0.024 & 1.099 & 0.93 & 0.353 \\
\hline Snack intake between meals & 0.036 & 1.526 & 1.40 & 0.163 \\
\hline Consideration for nutritional balance & -0.039 & -1.835 & -1.52 & 0.128 \\
\hline Coffee drinking & 0.044 & 1.930 & 1.67 & 0.096 \\
\hline Hours of walking at ordinary speed & 0.027 & 1.082 & 0.96 & 0.339 \\
\hline Hours of brisk walking & -0.011 & -0.446 & -0.40 & 0.687 \\
\hline Working hours & 0.015 & 0.506 & 0.56 & 0.575 \\
\hline Physical exercise & -0.002 & -0.069 & -0.07 & 0.946 \\
\hline Sleeping hours & -0.003 & -0.125 & -0.11 & 0.911 \\
\hline (Constant) & & 58.638 & 5.42 & $<0.001$ \\
\hline \multicolumn{5}{|c|}{ HDL cholesterol } \\
\hline Age & -0.048 & -0.093 & -1.96 & 0.050 \\
\hline Body mass index & -0.292 & -1.302 & -12.46 & $<0.001$ \\
\hline Alcohol intake & 0.169 & 2.839 & 7.13 & $<0.001$ \\
\hline Smoking & -0.209 & -3.032 & -8.47 & $<0.001$ \\
\hline Eating breakfast & 0.022 & 0.423 & 0.94 & 0.349 \\
\hline Snack intake between meals & -0.037 & -0.646 & -1.54 & 0.124 \\
\hline Consideration for nutritional balance & 0.078 & 1.519 & 3.31 & 0.001 \\
\hline Coffee drinking & 0.005 & 0.089 & 0.20 & 0.842 \\
\hline Hours of walking at ordinary speed & 0.065 & 1.077 & 2.49 & 0.013 \\
\hline Hours of brisk walking & 0.073 & 1.182 & 2.79 & 0.005 \\
\hline Working hours & 0.015 & 0.210 & 0.61 & 0.545 \\
\hline Physical exercise & 0.048 & 0.797 & 2.04 & 0.042 \\
\hline Sleeping hours & 0.004 & 0.067 & 0.16 & 0.875 \\
\hline (Constant) & & 78.456 & 18.90 & $<0.001$ \\
\hline
\end{tabular}

Variables and values of the study were as follows:

Age (years): exact values.

Body mass index $\left(\mathrm{kg} / \mathrm{m}^{2}\right)$ : exact values.

Alcohol intake ( $\mathrm{g} /$ day of ethanol): 1 for none, 2 for $\leq 45.9,3$ for $\geq 46.0$.

Smoking (cigarettes/day): 1 for none, 2 for $\leq 29,3$ for $\geq 30$.

Eating breakfast: 1 for hardly ever, 2 for sometimes, 3 for every morning.

Snack intake between meals: 1 for hardly ever, 2 for sometimes, 3 for every day.

Consideration for nutritional balance: 1 for hardly ever, 2 for sometimes, 3 for always.

Coffee drinking (cups/day): 1 for hardly ever, 2 for 1 or 2, 3 or more.

Hours of walking at ordinary speed (hours/day): 1 for $<0.5,2$ for $0.5-0.9,3$ for $\geq 1.0$.

Hours of brisk walking (hours/day): 1 for $<0.5,2$ for $0.5-0.9,3$ for $\geq 1.0$.

Working hours (hours/day): 1 for $\leq 8.0,2$ for $8.1-9.9,3$ for $\geq 10.0$.

Physical exercise (times/week): 1 for hardly ever, 2 for once, 3 for twice or more.

Sleeping hours (hours/night): 1 for $\leq 6.5,2$ for $6.5-7.4,3$ for $\geq 7.5$.

lipoprotein lipase (LPL) activity not only in skeletal muscle but also in adipose tissue and that the high HDL cholesterol levels of physically active people are probably accounted for, at least partly, by the increase in LPL activity and the concomitant rapid turnover of triglyceride-rich lipoproteins. In this study,
HDL cholesterol level was positively associated with physical exercise and the hours of walking at an ordinary pace and at a brisk pace. Furthermore, the hours of brisk walking showed a negative association with the ratio of LDL cholesterol to $\mathrm{HDL}$ cholesterol. We assume that for our population walking long 
Table 3. (continued) Multiple linear regression analyses of LDL cholesterol, HDL cholesterol and Log triglyceride levels and the ratio of LDL cholesterol to HDL cholesterol in relation to age and lifestyle factors.

\begin{tabular}{|c|c|c|c|c|}
\hline Variables & $\begin{array}{l}\text { Standardized } \\
\text { coefficient }\end{array}$ & $\begin{array}{l}\text { Natural } \\
\text { coefficient }\end{array}$ & $\mathrm{T}$ value & $P$ value \\
\hline \multicolumn{5}{|c|}{ Log triglyceride } \\
\hline Age & 0.031 & 0.003 & 1.22 & 0.222 \\
\hline Body mass index & 0.345 & 0.075 & 14.50 & $<0.001$ \\
\hline Alcohol intake & 0.057 & 0.047 & 2.37 & 0.018 \\
\hline Smoking & 0.143 & 0.102 & 5.71 & $<0.001$ \\
\hline Eating breakfast & -0.030 & -0.028 & -1.27 & 0.206 \\
\hline Snack intake between meals & -0.033 & -0.028 & -1.35 & 0.177 \\
\hline Consideration for nutritional balance & -0.073 & -0.070 & -3.06 & 0.002 \\
\hline Coffee drinking & -0.057 & -0.051 & -2.31 & 0.021 \\
\hline Hours of walking at ordinary speed & -0.010 & -0.008 & -0.39 & 0.700 \\
\hline Hours of brisk walking & -0.008 & -0.006 & -0.29 & 0.775 \\
\hline Working hours & -0.067 & -0.047 & -2.73 & 0.006 \\
\hline Physical exercise & -0.008 & -0.007 & -0.34 & 0.734 \\
\hline Sleeping hours & 0.029 & 0.026 & 1.21 & 0.225 \\
\hline (Constant) & & 3.047 & 14.79 & $<0.001$ \\
\hline \multicolumn{5}{|c|}{ Ratio of LDL cholesterol to HDL cholesterol } \\
\hline Age & 0.069 & 0.009 & 2.69 & 0.007 \\
\hline Body mass index & 0.290 & 0.085 & 11.91 & $<0.001$ \\
\hline Alcohol intake & -0.162 & -0.178 & -6.59 & $<0.001$ \\
\hline Smoking & 0.112 & 0.106 & 4.39 & $<0.001$ \\
\hline Eating breakfast & 0.004 & 0.005 & 0.16 & 0.870 \\
\hline Snack intake between meals & 0.051 & 0.057 & 2.03 & 0.043 \\
\hline Consideration for nutritional balance & -0.068 & -0.086 & -2.75 & 0.006 \\
\hline Coffee drinking & 0.033 & 0.039 & 1.29 & 0.198 \\
\hline Hours of walking at ordinary speed & 0.006 & 0.006 & 0.21 & 0.831 \\
\hline Hours of brisk walking & -0.060 & -0.063 & -2.20 & 0.028 \\
\hline Working hours & 0.001 & 0.001 & 0.04 & 0.967 \\
\hline Physical exercise & -0.032 & -0.035 & -1.31 & 0.190 \\
\hline Sleeping hours & 0.009 & 0.010 & 0.35 & 0.726 \\
\hline (Constant) & & 0.194 & 0.69 & 0.489 \\
\hline
\end{tabular}

Variables and values of the study were as follows:

Age (years): exact values.

Body mass index $\left(\mathrm{kg} / \mathrm{m}^{2}\right)$ : exact values.

Alcohol intake ( $g /$ day of ethanol): 1 for none, 2 for $\leq 45.9,3$ for $\geq 46.0$.

Smoking (cigarettes/day): 1 for none, 2 for $\leq 29,3$ for $\geq 30$.

Eating breakfast: 1 for hardly ever, 2 for sometimes, 3 for every morning.

Snack intake between meals: 1 for hardly ever, 2 for sometimes, 3 for every day.

Consideration for nutritional balance: 1 for hardly ever, 2 for sometimes, 3 for always.

Coffee drinking (cups/day): 1 for hardly ever, 2 for 1 or 2,3 or more.

Hours of walking at ordinary speed (hours/day): 1 for $<0.5,2$ for $0.5-0.9,3$ for $\geq 1.0$.

Hours of brisk walking (hours/day): 1 for $<0.5,2$ for $0.5-0.9,3$ for $\geq 1.0$.

Working hours (hours/day): 1 for $\leq 8.0,2$ for $8.1-9.9,3$ for $\geq 10.0$.

Physical exercise (times/week): 1 for hardly ever, 2 for once, 3 for twice or more.

Sleeping hours (hours/night): 1 for $\leq 6.5,2$ for $6.5-7.4,3$ for $\geq 7.5$.

hours, especially at a brisk pace, may be an important preventive modality for subjects with reduced levels of HDL cholesterol and increased ratios of LDL cholesterol to HDL cholesterol and may have a beneficial protective effect on CHD.

Several studies ${ }^{3941)}$ have reported that consumption of unfil- tered, boiled coffee is closely associated with raised serum cholesterol levels. The diterpenes cafestol and kahweol (nontriglyceride lipids present in coffee) are shown to be responsible for hypercholesterolemic effects of boiled coffee ${ }^{42,43)}$. On the other hand, instant or percolator coffee is reported to have 
negligible effects on serum cholesterol concentration because of their low concentration of cafestol and kahweol ${ }^{41,433}$. As for the triglyceride level, investigations into the effects of coffee consumption on triglycerides have variously found that it is either positively related ${ }^{44,45)}$ or negatively related ${ }^{41,46)}$ to increased level of triglyceride. Stensvold et al. ${ }^{41)}$ reported that the negative association between coffee and triglycerides was stronger for filtered coffee than for boiled coffee. In this study, there was no significant association between coffee consumption and LDL cholesterol level, but the independently negative association was found between coffee consumption and the triglyceride level. We did not obtain information regarding brewing methods of coffee, but instant coffee is most popular in Japan, followed by brewed (mostly filtered) coffee, whereas use of unfiltered coffee is virtually absent ${ }^{47}$, and the level of consumption was also lower in this study than in previous studies from outside Japan. Further investigation is needed to confirm whether coffee consumed in Japan has the effects on serum lipid levels in middle-aged Japanese men.

This study showed that consideration for nutritional balance was positively associated with HDL cholesterol level and negatively associated with triglyceride level and the ratio of LDL cholesterol to HDL cholesterol. Furthermore, the frequency of snack intake between meals was positively related to the ratio of LDL cholesterol to HDL cholesterol. These results suggest that dietary habits have close associations with serum lipid levels. We also found that hours of work had a negative association with triglyceride level. From the nutritional survey in this population, there were significant differences ( $p<0.001$, analysis of variance) among the consumed energy values for the three subgroups with regard to hours of work [2349 \pm 293 $\mathrm{kcal} /$ day for working $8 \mathrm{~h} /$ day or less, $2453 \pm 288 \mathrm{kcal} /$ day for working 8.1-9.9 h/day, and $2577 \pm 282 \mathrm{kcal} /$ day for working $10 \mathrm{~h} /$ day or more (mean \pm standard deviation)]. The negative association between triglyceride level and hours of work might be derived from the high consumption of energy related to working long hours.

This study has several limitations. First, nutrient intake was not included in the present analysis and may enhance the predictive value of the current findings or act as potentially confounding factors for BMI, smoking and alcohol consumption. Some investigators have reported that calories from alcohol supplement normal energy intake ${ }^{48,49)}$, whereas others have found that they replace energy intake from other sources, especially in heavy drinkers ${ }^{50}$. Second, because non-drinkers or non-smokers may have stopped drinking or smoking due to other diseases which might affect serum lipid and lipoprotein levels, calculations excluding those who had stopped drinking or smoking were performed, but the results were similar to those of the original ones. Third, the level or strength of exercise while at work was not evaluated in this study. All the subjects surveyed for this study were male office workers (architects $59.0 \%$, those in the general-duties grade $20.9 \%$, sales staffs $8.0 \%$ and others $12.1 \%$ ), and no one engaged in physical or muscular labor. Age-adjusted means of LDL cholesterol, HDL cholesterol, and Log triglyceride levels and the ratio of LDL cholesterol to HDL cholesterol were not significantly different among the four subgroups of job category, but the potential effect of the level or strength at work on serum lipids deserves further investigation. Fourth, waking speed was not measured quantitatively in the present study, and the questions used in this study may be too crude. Further investigations are needed to clarify how long we should walk a day and what speed is appropriate at walking for promoting better health.

Despite these potential limitations, our findings present that obesity, current cigarette smoking and the frequency of snack intake between meals are closely associated with an increased risk of atherogenic lipid profiles. On the other hand, alcohol consumption, consideration for nutritional balance and walking long hours, especially at a brisk pace, may have an anti-atherogenic effect by altering serum lipid profiles in middle-aged Japanese men.

\section{ACKNOWLEDGMENTS}

We would like to express our appreciation to all the employees and the Medical Office of the Osaka Main Office of Takenaka Corporation for their valuable cooperation for this study. We are also grateful to Ryuichi Kaneko and his colleagues at the Japan Labor and Welfare Association for their accurate collecting and coding of the data. This study was supported in part by Grand-in-Aid for the prevention of life-style related diseases from the Arteriosclerosis Prevention Association, Tokyo, Japan.

\section{REFERENCES}

1. Miller NE, Hammett F, Saltissi S, et al. Relation of angiographically defined coronary artery disease to plasma lipoprotein subfractions and apoproteins. $\mathrm{Br}$ Med J 1981;282:1741-4.

2. Castelli WP, Doyle JT, Gordon T, et al. HDL cholesterol and other lipids in coronary heart disease. The cooperative lipoprotein phenotyping study. Circulation 1977;55:767-72.

3. Kannel WB. High-density lipoproteins: Epidemiologic profile and risk of coronary artery disease. Am J Cardiol 1983;52:9B-12B.

4. Grundy SM, Mok HY, Zech L, Steinberg D, Berman M. Transport of very low density lipoprotein triglycerides in varying degrees of obesity and hypertriglyceridemia. $\mathbf{J}$ Clin Invest 1979;63:1274-83.

5. Gordon T, Fisher M, Ernst N, Rifkind BM. Relation of diet to LDL cholesterol, VLDL cholesterol, and plasma total cholesterol and triglycerides in white adults: The Lipid Research Clinics Prevalence Study. Arteriosclerosis 
1982;2:502-12.

6. Yano K, Reed DM, Curb JD, Hankin JH, Albers JJ. Biological and dietary correlates of plasma lipids and lipoproteins among elderly Japanese men in Hawaii. Arteriosclerosis 1986;6:422-33.

7. Denke MA, Sempos CT, Grundy SM. Excess body weight. An underrecognized contributor to high blood cholesterol levels in white American men. Arch Intern Med 1993;153:1093-103.

8. Choudhury SR, Ueshima H, Kita Y, et al. Alcohol intake and serum lipids in a Japanese population. Int $\mathbf{J}$ Epidemiol 1994; 23: 940-7.

9. Criqui MH, Wallace RB, Heiss G, et al. Cigarette smoking and plasma high-density lipoprotein cholesterol. The Lipid Research Clinics Program Prevalence Study. Circulation 1980; 62 (suppl IV):70-6.

10. Phillips NR, Havel RJ, Kane JP. Levels and interrelationships of serum and lipoprotein cholesterol and triglycerides. Association with adiposity and the consumption of ethanol, tobacco, and beverages containing caffeine. Arteriosclerosis 1981;1:13-24.

11. Hegarty KM, Turgiss LE, Mulligan JJ, et al. Effects of cigarette smoking on high density lipoprotein phospholipids. Biochem Biophys Res Commun 1982;104:212-9.

12. Castelli WP, Doyle JT, Gordon T, et al. Alcohol and blood lipids. The cooperative lipoprotein phenotyping study. Lancet 1977;ii:153-5.

13. Ernst N, Fisher M, Smith W, et al. The association of plasma high-density lipoprotein cholesterol with dietary intake and alcohol consumption. The Lipid Research Clinics Prevalence Study. Circulation 1980; 62 (suppl IV):41-52.

14. Frimpong NA, Lapp JA. Effects of moderate alcohol intake in fixed or variable amounts on concentration of serum lipids and liver enzymes in healthy young men. Am J Clin Nutr 1989;50:987-91.

15. Nikkila EA, Taskinen MR, Rehunen S, Harkonen M. Lipoprotein lipase activities in adipose tissue and skeletal muscle of runners: relation to serum lipoproteins. Metabolism 1978;27:1661-71.

16. Huttunen JK, Lansimies E, Voutilainen E, et al. Effects of moderate physical exercise on serum lipoproteins. A controlled clinical trial with special reference to serum highdensity lipoprotein. Circulation 1979;60:1220-9.

17. Haskell WL. Exercise-induced changes in plasma lipids and lipoproteins. Prev Med 1984;13:23-36.

18. Wood PD, Stefanick ML, Dreon DM, et al. Changes in plasma lipids and lipoproteins in overweight men during weight loss through dieting as compared with exercise. $\mathbf{N}$ Engl J Med 1988;319:1173-9

19. Linn S, Fulwood R, Carroll M, et al. Serum total cholesterol: HDL cholesterol ratios in USA white and black adults by selected demographic and socioeconomic vari- ables (HANES II). Am J Public Health 1991;81:1038-43.

20. Young TK, Gelskey DE. Is noncentral obesity metabolically benign? Implications for prevention from a population survey. JAMA 1995;274:1939-41.

21. Belloc NB, Breslow L. Relationship of physical health status and health practice. Prev Med 1972;1:409-21.

22. Morimoto K, Kaneko T, lijima K, Koizumi A. Human health situation and chromosome alterations: Sister chromatid exchange frequency in lymphocytes from passive smokers and patients with hereditary disease. In: Tice $\mathbf{R}$, Hollaender A, Lambert B, Morimoto K, editors. Sister Chromatid Exchanges: Genetic Toxicology Human Studies. New York: Plenum, 1984: 501-812.

23. Friedewald WT, Levy RI, Fredrickson DS. Estimation of the concentration of low-density lipoprotein cholesterol in plasma, without use of the preparative ultracentrifuge. Clin Chem 1972; 18:499-502.

24. Hubert HB, Feinleib M, McNamara PM, Castelli WP. Obesity as an independent risk factor for cardiovascular disease: a 26-year follow-up of participants in the Framingham Heart Study. Circulation 1983;67:968-77.

25. Berchtold $P$, Jorgens V, Finke $C$, Berger $M$. Epidemiology of obesity and hypertension. Int $\mathbf{J}$ Obesity 1981;5 (suppl 1):1-7.

26. Blair D, Habicht JP, Sims EA, Sylwester D, Abraham $S$. Evidence for an increased risk for hypertension with centrally located body fat and the effect of race and sex on this risk. Am J Epidemiol 1984; 1 19:526-40.

27. Hartz AJ, Rupley DC Jr, Kalkhoff RD, Rimm AA. Relationship of obesity to diabetes: influence of obesity level and body fat distribution. Prev Med 1983;12:351-7.

28. Stern MP, Haffner SM. Body fat distribution and hyperinsulinemia as risk factors for diabetes and cardjovascular disease. Arteriosclerosis 1986;6:123-30.

29. Caggiula AW, Christakis G, Farrand M, et al. The multiple risk factor intervention trial (MRFIT). IV. Intervention on blood lipids. Prev Med 1981;10:443-75.

30. Gordon DJ, Salz KM, Roggenkamp KJ, Franklin FA Jr. Dietary determinants of plasma cholesterol change in the recruitment phase of the Lipid Research Clinics Coronary Primary Prevention Trial. Arteriosclerosis 1982;2:537-48.

31. Marmot MG, Rose G, Shipley MJ, Thomas BJ. Alcohol and mortality: a U-shaped curve. Lancet $1981 ; \mathrm{i}: 580-3$.

32. Criqui MH. The roles of alcohol in the epidemiology of cardiovascular diseases. Acta Med Scand 1987;717 (suppl):73-85.

33. Klatsky AL, Armstrong MA, Friedman GD. Risk of cardiovascular mortality in alcohol drinkers, ex-drinkers and nondrinkers. Am J Cardiol 1990;66:1237-42.

34. Kitamura A, Iso $H$, Sankai $T$, et al. Alcohol intake and premature coronary heart disease in urban Japanese men. Am J Epidemiol 1998; 147: 59-65.

35. Criqui MH, Cowan LD, Tyroler HA, et al. Lipoproteins 
as mediators for the effects of alcohol consumption and cigarette smoking on cardiovascular mortality: results from the lipid research clinics follow-up study. Am J Epidemiol 1987;126:629-37.

36. Suh I, Shaten BJ, Cutler JA, Kuller LH. Alcohol use and mortality from coronary heart disease: the role of highdensity lipoprotein cholesterol. The Multiple Risk Factor Intervention Trial Research Group. Ann Intern Med 1992;116:881-7.

37. Renaud S, De Lorgeril M. Wine, alcohol, platelets, and the French paradox for coronary heart disease. Lancet 1992;339:1523-6.

38. Renaud SC, Beswick AD, Fehily AM, Sharp DS, Elwood PC. Alcohol and platelet aggregation: the Caerphilly Prospective Heart Disease Study. Am J Clin Nutr 1992;55:1012-7.

39. Aro A, Teirila J, Gref CG. Dose-dependent effect on serum cholesterol and apoprotein B concentrations by consumption of boiled, non-filtered coffee. Atherosclerosis 1990;83:257-61.

40. Bak AA, Grobbee DE. The effect on serum cholesterol levels of coffee brewed by filtering or boiling. $\mathrm{N}$ Engl J Med 1989;321:1432-7.

41. Stensvold I, Tverda A, Foss OP. The effect of coffee on blood lipids and blood pressure. Results from a Norwegian cross-sectional study, men and women, 40-42 years. J Clin Epidemiol 1989;42:877-84.
42. Wensten Van der Woum MP, Katan MB, Viani R, et al. Identify of the cholesterol-raising factor from boiled coffee and its effects on liver function enzymes. J Lipid Res 1994;35:721-33.

43. Urgert R, Van der Weg G, Kosmeijer-Schuil TG, et al. Levels of the cholesterol-elevating diterpenes cafestol and kahweol in various coffee brews. J Agric Food Chem 1995;43:2167-72.

44. Thelle DS, Arnesen E, Førde OH. The Troms $\emptyset$ Heart Study. Does coffee raise serum cholesterol? N Engl J Med 1983;308:1454-7.

45. Williams PT, Wood PD, Vranizan KM, et al. Coffee intake and elevated cholesterol and apolipoproten B levels in men. JAMA 1985;253:1407-11.

46. Phillips NR, Havel RJ, Kanel JP. Levels and interrelationships of serum and lipoprotein cholesterol and triglycerides. Atherosclerosis 1981;1:13-24.

47. All Japan Coffee Association. A Basic Survey for Monitoring Trends in the Demand for Coffee (Japanese with English Abstract). Tokyo: All Japan Coffee Association, 1995.

48. Fisher M, Gordon $\mathbf{T}$. The relation of drinking and smoking habits to diet: the Lipid Research Clinics Prevalence Study. Am J Clin Nutr 1985;41:623-30.

49. Jones BR, Barrett-Connor E, Criqui MH, et al. A community study of calorie and nutrient intake in drinkers and nondrinkers of alcohol. Am J Clin Nutr 1982;35:135-9. 